\title{
Strain differences in hypothalamic-pituitary-adrenocortical axis function and adipogenic effects of corticosterone in rats
}

\author{
Nathalie Marissal-Arvy, Alexandra Gaumont, Allan Langlois, Fabrice Dabertrand, \\ Marion Bouchecareilh ${ }^{1}$, Claudine Tridon and Pierre Mormede \\ Laboratoire PsyNuGen, INRA UMR1286, CNRS UMR5226, Université de Bordeaux 2, 146 rue Léo-Saignat, F-33076 Bordeaux, France \\ ${ }^{1}$ Laboratoire des Régulations Neuroendocriniennes, EA2972, Université de Bordeaux 1, Avenue des Facultés, F-33405 Talence, France \\ (Correspondence should be addressed to N Marissal-Arvy; Email: marissal@bordeaux.inserm.fr)
}

\begin{abstract}
Our aim was to explore the nutritional consequences of functional variations in the hypothalamic-pituitary-adrenocortical (HPA) axis in rats. We first aimed to compare the HPA axis activity and reactivity to stress between Fischer 344 (F344) and LOU/C (LOU) strains that differ in food behavior and metabolism. When compared with F344 rats, LOU rats showed lower corticosterone (Cort) levels across the circadian cycle and after restraint stress. Then, we compared the effects of adrenalectomized (ADX) and Cort substitution after ADX on food intake, body weight gain, body composition, and biochemical parameters related to metabolism and HPA axis function between 1) the F344 rat strain, a model of HPA axis hyperactivity and hyperreactivity to stress, and characterized by a large fat mass; 2) the LOU strain, shown to exhibit hypoactive/hyporeactive HPA axis, reduced fat mass, and resistance to diet-induced obesity; and 3) the Lewis (LEW)
\end{abstract}

strain, a third condition of fat deposition (high) related to HPA axis function (low activity/reactivity). The F344 and LEW strains exhibited classical responses to ADX and Cort. On the contrary, LOU rats showed an apparent insensitivity to ADX. Despite the highest effects of Cort related to glucocorticoid receptor (on thymus weight, corticotropinreleasing factor, or corticosteroid-binding globulin), the LOU strain was insensitive to Cort effects on body weight, liver, and abdominal fat mass. These characteristics could be involved in the leanness, insensitivity to diet-induced obesity, and healthy aging in LOU. Our study shows the relevance of comparing the F344, LOU, and LEW strains to cover the complexity of interactions between metabolism and HPA axis function.

Journal of Endocrinology (2007) 195, 473-484

\section{Introduction}

Prevalence of obesity in humans continues to increase in industrialized countries, mainly in children, which constitutes a pressing problem of public health in the industrialized world. Obesity results from an imbalance between caloric intake and energy expenditure, which induces body fat accumulation. This body fat excess leads to severe metabolic disturbances (e.g., hyperglycemia, hyperlipidemia, hyperinsulinemia) that are not only involved in the pathological consequences of obesity such as hypertension, type 2 diabetes, or cancer, but also in aggravating factors of adipogenesis (Girod \& Brotman 2003). However, the response to environmental pressure (sedentary life, fat-, and sugar-rich foods) shows high interindividual variation, and the involvement of genetic factors in this variability has been demonstrated by family and twin studies in humans ( $\mathrm{Li}$ et al. 2005, Loos \& Rankinen 2005), the comparison of inbred strains (Schalling et al. 1999) and selection experiments in animals (Levin et al. 1997). A key process involved in this variability

lies in the responsivity of the hypothalamic-pituitaryadrenocortical (HPA) axis. Indeed, corticosteroid hormones are implicated in nutritional regulations 1) by their action on central monoaminergic systems and hypothalamic peptides controlling food intake (Gibson 2006), and on the autonomous nervous system regulating thermogenesis and pancreatic secretions (Seematter et al. 2004) and 2) by a tissue-specific peripheral alteration of body reserves of carbohydrates (liver and muscles), proteins (muscular mass), and fats (white adipose tissue; Schalling et al. 1999).

Our aim was to explore the nutritional consequences of genetic variation in the HPA axis by the comparison of three inbred rat strains, Fischer 344 (F344), LOU/C (LOU), and Lewis (LEW). The F344 strain has been classically used as a model of HPA axis hyperactivity and hyperreactivity to stress, often in comparison with the LEW strain, of which the hypoactive and hyporeactive HPA axis has been associated with its vulnerability to autoimmune diseases (Dhabbar et al. 1995). When compared with other strains, the LOU rat strain exhibits healthy aging and lower fat mass (Alliot et al. 2002, Veyrat-Durebex et al. 2005). We have also 
shown that, in contrast to the diet-induced development of visceral obesity in F344 and LEW rats (Nave et al. 2003, Helies et al. 2005), LOU rats were resistant to diet-induced obesity (Helies et al. 2005). F344 rats have also been described as storing excess triglycerides in liver and muscle. They exhibit insulin and leptin resistance and dyslipidemia associated with abdominal fat accumulation (Levy et al. 2002). Considering the disturbances in the function of HPA axis playing a 'permissive' role in metabolic troubles linked to obesity (Ljung et al. 2002), we hypothesized that the nutritional differences observed between F344, LOU, and LEW rats could be related to the functional differences revealed in the HPA axis.

The first part of our study aimed to compare the HPA axis function between LOU and F344 rat strains. To that end, we measured corticosterone secretion during the circadian cycle and during recovery following restraint and metabolic stress (insulin-induced hypoglycemia) in both strains. Then, to unravel the network of interactions between the components of the HPA axis and to remove any strain differences in corticosterone availability, F344, LOU, and LEW male rats were adrenalectomized (ADX) and treated with increasing and fixed doses of corticosterone administered by s.c. pellets $(0-100 \mathrm{mg})$. LEW rats were added to the study of F344 and LOU rats in order to introduce a third condition of fat deposition related to the HPA axis function. Therefore, in the second experiment, we compared the effects of ADX and corticosterone substitution on food intake, body composition, parameters related to metabolism (plasma glucose, insulin, free fatty acids, and leptin), and parameters related to the HPA axis function (corticotropin-releasing factor (CRF) expression in the hypothalamic paraventricular nucleus, plasma adrenocorticotropic hormone (ACTH), and corticosteroid-binding globulin (CBG)) between F344 (hyperactive HPA axis, large fat mass), LOU (hypoactive HPA axis, low fat mass), and LEW rats (hypoactive HPA axis, large fat mass).

\section{Materials and Methods}

\section{Animals, general}

Experiments were performed in accordance with the principles and guidelines of the French legislation on animal welfare: Journal Official number 87-848. All animals were born and raised in the laboratory from LOU (strain previously supplied by Harlan, Gannat, France), LEW, and F344 breeders (Iffa Credo, L'Arbresle, France). Rats were housed in standard collective cages, in a temperature-controlled room $\left(23 \pm 1{ }^{\circ} \mathrm{C}\right)$ with a $12 \mathrm{~h}$ light: $12 \mathrm{~h}$ darkness cycle (lights on at $0700 \mathrm{~h})$. They were fed with SAFE-A03 chow $(3 \cdot 2 \mathrm{kcal} / \mathrm{g}$ metabolizable energy, Scientific Animal Food \& Engineering, Villemoisson-sur-Orge, France) until weaning at 28 days of age, and subsequently with SAFE-A04 $(2.9 \mathrm{kcal} / \mathrm{g}$ metabolizable energy). Water was available ad libitum. All rats were allowed to adapt to the animal room and placed two per cage for 10 days before the start of the experiments.

\section{Experiment 1}

Animals Our first experiment aimed to explore the HPA axis activity and reactivity to psychological and metabolic stress in LOU and F344 rats. It was conducted in 12-week-old males and females. The same rat cohort $(n=8$ per sex and strain) was randomly used for basal and restraint stress measurements. Another cohort $(n=8$ per sex and strain) was used for the insulin-induced hypoglycemic stress. Stress experiments were performed between 0900 and $1100 \mathrm{~h}$.

Blood sampling under basal conditions Rats were removed from their home cage, and blood was taken from a nick of the tail, within $1 \mathrm{~min}$ for every $6 \mathrm{~h}$ at 0000,0600 , 1200 , and $1800 \mathrm{~h}$ to measure basal plasma corticosterone levels throughout the circadian cycle.

Restraint stress Rats were restrained for a period of $20 \mathrm{~min}$ in plastic bags with a breathing hole (Harvard Apparatus, Ealing, Courtaboeuf, France) between 0900 and $1100 \mathrm{~h}$ as described previously (Chaouloff 1994). In $<1 \mathrm{~min}$ from placement in the restraint, blood samples were collected from a nick of the tail for the measurement of basal (T0), stress peak $(\mathrm{T} 0+50 \mathrm{~min})$, and recovery $(\mathrm{T} 0+110 \mathrm{~min})$ values of plasma corticosterone concentration (times were chosen following our previous results; Sarrieau \& Mormede 1998, Sarrieau et al. 1998).

Insulin-induced hypoglycemic stress F344 and LOU rats were fasted overnight before the test. Rats were removed from their home cage, and blood was taken from a nick of the tail in order to measure basal plasma glucose and corticosterone concentrations (T0). Two minutes later, rats were injected i.p. with insulin (Actrapid Humarin, NOVONordisk, Mainz, Germany, $4 \mathrm{IU} / \mathrm{kg}$ ). Then, blood samples were collected at $\mathrm{T} 0+30 \mathrm{~min}$ and $\mathrm{T} 0+90 \mathrm{~min}$ as described above, and in the literature (Karteszi et al. 1982, Osako et al. 1999).

Plasma measurements Samples were collected in chilled tubes coated with $10 \%$ EDTA solution and centrifuged at $4000 \mathrm{~g}$ for $15 \mathrm{~min}$ at $4{ }^{\circ} \mathrm{C}$. Plasma was then stored at $-80{ }^{\circ} \mathrm{C}$ for subsequent measurements of corticosterone and glucose. Plasma glucose levels were measured in duplicate by the glucose oxidase technique with a colorimetric kit (Biolabo, Maizy, France). Corticosterone concentrations were measured in duplicate by RIA with a commercial kit (MP Biomedicals, Orangeburg, NY, USA).

Data analysis Results were expressed as means \pm s.E.M. Data were analyzed by a three-way ANOVA with strain (F344, LOU) and sexes as two between-subject factors, and time as within-repeated factor. Post hoc Newman-Keuls tests were performed when ANOVA was significant $(P<0 \cdot 05)$. 


\section{Experiment 2}

To test the assumption of an association between differences in the HPA axis function and nutritional differences in rats, we compared the effects of ADX and corticosterone substitution after ADX on food intake, body weight gain, body composition, and biochemical parameters related to metabolism and the HPA axis function between the F344, LOU, and LEW rat strains. We restricted this study to a male rat population in order to lighten the results discussed in this publication, and to allow us to refer to previous works concerning metabolism or HPA axis function, which were mostly carried out in males.

Animals Bilateral ADX (40 rats per strain, in two successive replications) was performed under pentobarbital anesthesia $(0 \cdot 1 \mathrm{ml} / 100 \mathrm{~g}$ of body weight) on 12-week-old LOU, F344, and LEW males. Sham-operated animals (eight rats per strain, in two successive replications) were subjected to anesthesia and bilateral laparotomy. Incisions were closed with surgical gut and wound clips. At the time of surgery, a pellet was implanted subcutaneously in the interscapular region of each rat. Shamoperated animals and eight ADX rats of each strain received paraffin pellets weighing about $100 \mathrm{mg}$ (Sham and ADX +0 groups respectively). The other ADX rats were given $100 \mathrm{mg}$ fused pellets composed of various percentages of corticosterone and cholesterol, and distributed among four experimental groups, $\mathrm{ADX}+12 \cdot 5, \mathrm{ADX}+25, \mathrm{ADX}+50$, and $\mathrm{ADX}+100$, treated with pellets containing $12 \cdot 5,25,50$, and $100 \%$ of corticosterone respectively. The pellets remained in situ until killing. The percentages of corticosterone used in pellets were chosen in order to cover mineralocorticoid receptor (MR; from 12.5 to $25 \%$ ) and then glucocorticoid receptor (GR; from $25 \%$ ) activation, and according to previous studies investigating physiological regulations by corticosterone in rats (Levin et al. 1987, Duclos et al. 2004). All rats were given saline $(0 \cdot 5 \% \mathrm{NaCl})$ after surgery. Animals, food, and drinking fluid were weighed every 2 days for 2 weeks. Then, rats were fasted overnight, weighed, and killed by decapitation (from 0900 to $1100 \mathrm{~h}$ ).

Body composition Four depots of adipose tissue were carefully removed and weighed: epididymal (around testis and ductus deferens), retroperitoneal (along the posterior wall, from the kidney to the hip region), mesenteric (along the mesentery, starting from the lesser curvature of the stomach and ending at the sigmoid colon), and inguinal (s.c. fat between the lower part of the rib cage and the thighs). Liver and thymus were also excised and weighed.

CRF expression in the paraventricular nucleus Brains were dissected out, embedded in Tissue Tek (Sakura Finetek Europe BV, Zoeterwoude, The Netherlands), frozen in isopentane cooled at $-50{ }^{\circ} \mathrm{C}$, and stored at $-80{ }^{\circ} \mathrm{C}$. Coronal sections were cut at $12 \mu \mathrm{m}$ in a cryostat, collected onto gelatinized slides, and stored at $-80{ }^{\circ} \mathrm{C}$ until use. Hybridization procedure was conducted as described previously
(Ribot et al. 2003) with a radioactive antisense cRNA CRF probe. The hybridization signal was analyzed by macroautoradiography over the paraventricular nucleus area in three adjacent series of eight sections spaced $72 \mu \mathrm{m}$.

Hormonal and biochemical parameters ACTH, CBG, corticosterone, glucose, nonesterified free fatty acids (FFA), insulin, and leptin concentrations were measured in plasma. Trunk blood was collected into chilled tubes coated with 10\% EDTA solution and centrifuged $(4000 \mathrm{~g}, 15 \mathrm{~min}$, $4{ }^{\circ} \mathrm{C}$ ) in order to extract plasma, which was stored at $-80^{\circ} \mathrm{C}$.

HPA axis Plasma ACTH was measured in duplicate with an RIA kit (ACTH Radioisotopic Assay, Nichols Institute Diagnostics, San Juan Capistrano, CA, USA).

CBG concentration was measured by competitive protein binding between cold corticosterone and ${ }^{3} \mathrm{H}$-corticosterone in a $50 \mu \mathrm{l}$ plasma volume (Johnson et al. 2005). Endogenous steroids were first removed with dextran-coated charcoal (DCC). After centrifugation to remove DCC $\left(9000 \mathrm{~g}, 15 \mathrm{~min}, 4^{\circ} \mathrm{C}\right)$, the supernatants were diluted 100 times in a Tris- $\mathrm{HCl}$ buffer $(\mathrm{pH} 7 \cdot 4)$ and incubated with $1 \cdot 50-200 \mathrm{nM}^{3} \mathrm{H}$-corticosterone in the presence (non-specific binding) or absence (specific binding) of $0 \cdot 8-100 \mu \mathrm{M}$ unlabeled steroid for $20 \mathrm{~min}$ at $40^{\circ} \mathrm{C}$, and for $2 \mathrm{~h}$ at $4{ }^{\circ} \mathrm{C}$. Separation of CBG-bound steroid was achieved by incubation with DCC $\left(10 \mathrm{~min}\right.$ at $\left.4{ }^{\circ} \mathrm{C}\right)$, followed by centrifugation $\left(2000 \mathrm{~g}, 15 \mathrm{~min}\right.$ at $\left.4{ }^{\circ} \mathrm{C}\right)$. The supernatants $(200 \mu \mathrm{l})$ were added to $3.5 \mathrm{ml}$ scintillating liquid and subjected to $\beta$-counting. Saturation curves were analyzed by Scatchard analysis with Prism software (GraphPad, San Diego, CA, USA).

Corticosterone concentrations were determined as described in experiment 1.

Metabolism Plasma glucose and FFA were measured in duplicate with colorimetric kits (Biolabo and Wako Chemicals, Neuss, Deutschland respectively). Plasma insulin and leptin were measured in triplicate with RIA kits (Insik 5, DiaSorin SA, Antony, France, and Linco Research, St Charles, MO, USA respectively).

Data analysis Results were expressed as means \pm S.E.M. Data were analyzed by a three-way ANOVA with strain (F344, LOU and LEW) and treatments (effect of corticosterone substitution treatments versus Sham or ADX +0 values) as two between-subject factors, and time as within-repeated factor when necessary (food and fluid intake, body weight gain). Post hoc Newman-Keuls tests were performed when ANOVA was significant $(P<0 \cdot 05)$.

\section{Results}

\section{Experiment 1}

The HPA axis activity and reactivity to psychological and metabolic stress in LOU and F344 rats were explored in this experiment. 
Circadian cycle of corticosterone secretion In both sexes, F344 rats exhibited a higher secretion of corticosterone than LOU rats during the darkness period (strain effect: $F_{1,119}=27 \cdot 82, P<0 \cdot 001 ;$ strain $\times$ time interaction: $F_{3,117}=$ $4 \cdot 88, P<0 \cdot 01$; Fig. 1a). The circadian cycle in female rats was more pronounced than in males (sex $\times$ time interaction: $\left.F_{3,117}=5 \cdot 17, P<0 \cdot 01\right)$.

Response to a restraint stress The restraint stress increased plasma corticosterone in both sexes and both strains (time effect: $F_{2,85}=66 \cdot 50, P<0 \cdot 001$; Fig. $1 \mathrm{~b}$ ), but to a greater extent in females than in males (sex $\times$ time interaction: $F_{2,85}=$ $7 \cdot 53, P<0 \cdot 001$ ), and more in F344 than in LOU rats (strain $X$ time interaction: $\left.F_{2,85}=4 \cdot 45, P<0 \cdot 01\right)$.

Response to insulin-induced hypoglycemia Plasma glucose levels. Insulin decreased glucose levels 30 and $90 \mathrm{~min}$ after injection in both sexes and both strains (time effect: $F_{2,88}=154 \cdot 39, P<0 \cdot 001$; Fig. 2 a), but significantly more in LOU than in F344 rats (strain $\times$ time interaction: $F_{2,88}=$ 25.08, $P<0 \cdot 001)$.

Plasma corticosterone levels. F344 rats exhibited higher plasma corticosterone concentrations than LOU rats (strain effect: $F_{1,89}=6 \cdot 90, P<0 \cdot 05$; Fig. $2 b$ ). Plasma corticosterone was increased by insulin injection in both sexes (time effect: $F_{2,88}=113 \cdot 37, P<0 \cdot 001$ ), but to a greater extent in females than in males (sex $\times$ time interaction: $\left.F_{2,88}=17 \cdot 24, P<0 \cdot 001\right)$.

\section{Experiment 2}

This experiment allowed us to compare the effects of ADX and corticosterone substitution after ADX on food intake, body weight gain, body composition, and biochemical parameters related to metabolism and the HPA axis function between the F344, LOU, and LEW rat strains.

In vivo measurements Saline and food intake. ADX increased strongly the saline intake of the three strains (treatment effect: $F_{5,67}=5 \cdot 24, P<0 \cdot 001$; Table 1), and particularly in LEW rats (strain $\times$ treatment interaction: $\left.F_{10,134}=3 \cdot 21, P<0 \cdot 05\right)$. Saline intake was not altered by corticosterone treatment in any strain. Food intake was not significantly different between groups or between treatments.

Body weight gain. Initial body weight did not differ across experimental groups in each strain. The percentages of weight gain or loss are presented in Table 1. During the first day of experimental procedures, F344 and LEW rats showed higher body weights than LOU rats (strain effect: $F_{2,142}=264 \cdot 35$, $P<0 \cdot 001)$. ADX induced weight loss in F344 and LEW rats

\section{Circadian cycle}

Males



Females

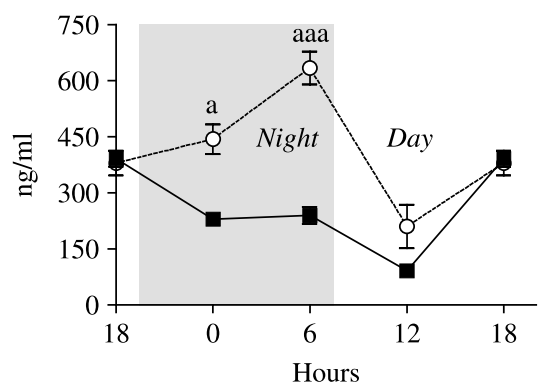

Stress effect

Males

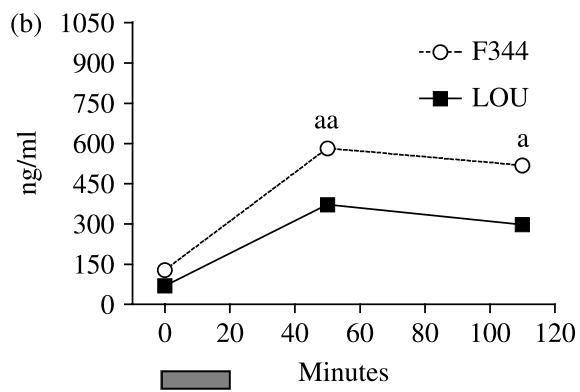

Stress

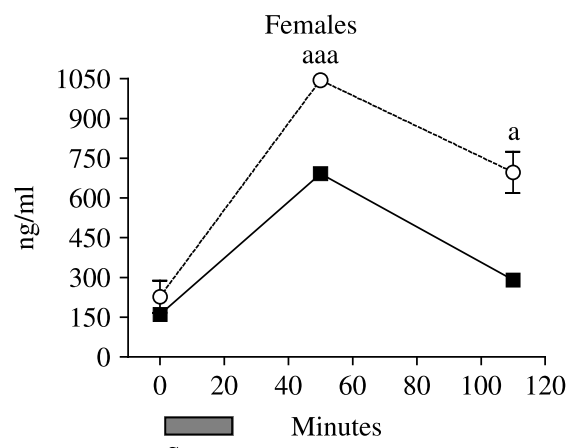

Stress

Figure 1 Plasma corticosterone (a) during the circadian cycle and (b) after a restraint stress. Strain differences: ${ }^{\text {a }} P<0 \cdot 05,{ }^{\text {aa }} P<0 \cdot 01$, aaa $P<0 \cdot 001$. 

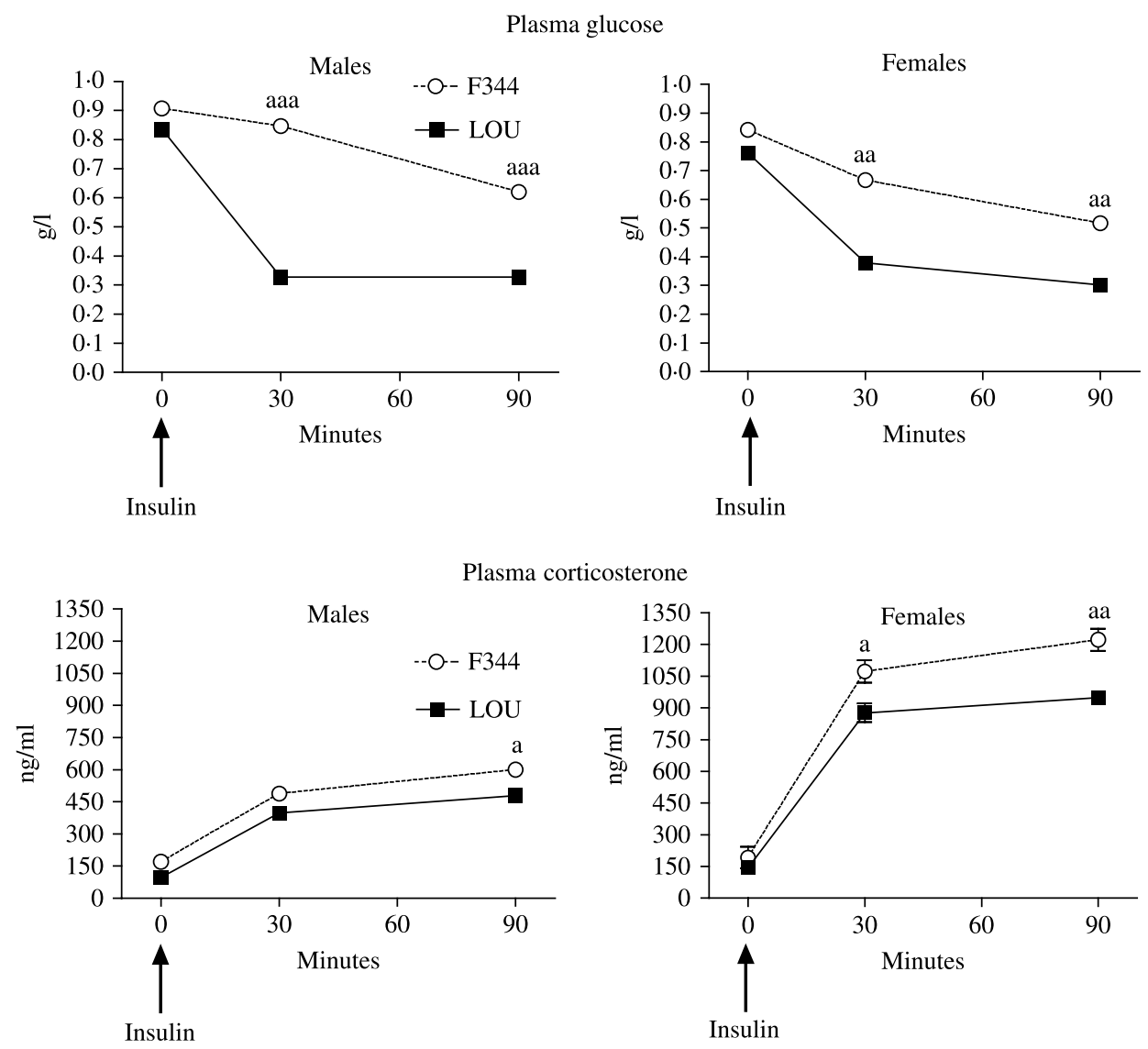

Figure 2 Plasma glucose and corticosterone concentrations in response to the hypoglycemic stress induced by insulin. F344 and LOU rats were fasted overnight before the test. Rats were removed from their home cage and blood was taken from a nick of the tail before (T0) and after insulin injection at $4 \mathrm{IU} / \mathrm{kg}$ $(\mathrm{T} 0+30 \mathrm{~min}, \mathrm{~T} 0+90 \mathrm{~min})$. Strain differences: ${ }^{\text {a }} P<0 \cdot 05$, aa $P<0 \cdot 01$, aaa $P<0 \cdot 001$.

Table 1 Total saline intake, food intake, and body weight (BW) gain during the 2 weeks after adrenalectomy (ADX) in Fischer 344 (F344), LOU, and Lewis (LEW) rats

\section{Treatment}

\begin{tabular}{|c|c|c|c|c|c|c|c|}
\hline & Strain & $\overline{\mathrm{ADX}}+0$ & $\mathrm{ADX}+12 \cdot 5$ & $\mathrm{ADX}+25$ & $\mathrm{ADX}+50$ & $\mathrm{ADX}+100$ & Sham \\
\hline \multicolumn{8}{|l|}{ Data } \\
\hline Saline intake & 344 & $57 \cdot 4 \pm 12 \cdot 4^{a}$ & $70 \cdot 8 \pm 12 \cdot 5^{a}$ & $72 \cdot 1 \pm 8 \cdot 6^{\mathrm{a}}$ & $51 \cdot 4 \pm 5 \cdot 5^{\mathrm{a}}$ & $55 \cdot 0 \pm 1 \cdot 7^{\mathrm{a}}$ & $47 \cdot 8 \pm 2 \cdot 5^{a}$ \\
\hline \multirow{2}{*}{ (ml/100 g BW/14 days) } & LOU & $58 \cdot$ & $77 \cdot 3 \pm 13 \cdot 7^{a}$ & $63 \cdot 3 \pm 3 \cdot 9^{a}$ & $58 \cdot 6 \pm 1 \cdot 9^{a}$ & 65 & $62 \cdot 0 \pm 7 \cdot 9$ \\
\hline & LEW & $88 \cdot 0$ & $106 \cdot 7 \pm 13 \cdot 0^{b}$ & $107 \cdot 9 \pm 12 \cdot 0^{b}$ & $86 \cdot 4 \pm 2 \cdot 2^{b}$ & $80 \cdot 4$ & $51 \cdot 0 \pm 1 \cdot 9^{+}$ \\
\hline Food intake & F344 & $37 \cdot 4$ & $52 \cdot 1 \pm 5 \cdot 5$ & $54 \cdot 0 \pm 7 \cdot 7$ & $47 \cdot 9$ & 5 & $69 \cdot 5 \pm 15 \cdot 6$ \\
\hline \multirow[t]{2}{*}{ (g/100 g BW/14 days) } & LOU & $\cdot 0$ & $\cdot 6$ & 58 & $58 \cdot 6$ & 60. & $62 \cdot 4 \pm 13 \cdot 7$ \\
\hline & LEW & $39 \cdot 7 \pm 8 \cdot 2$ & $53 \cdot 6 \pm 9 \cdot 0$ & $57 \cdot 0 \pm 9 \cdot 8$ & $62 \cdot 0 \pm 12 \cdot 2$ & $65 \cdot 1 \pm 14 \cdot 1$ & $64 \cdot 8 \pm 12 \cdot 7$ \\
\hline BW gain & F344 & $-11 \cdot 0 \pm 5 \cdot 0^{a}$ & $-2 \cdot 3 \pm 2 \cdot 6^{*}$ & $-3 \cdot 5 \pm 2 \cdot 4 *$ & $-6 \cdot 6 \pm 2 \cdot 6^{a}$ & $-1 \cdot 9 \pm 1 \cdot 4^{a, *}$ & $1 \cdot 5 \pm 1 \cdot 6^{+}$ \\
\hline \multirow{2}{*}{ (g/100 g BW/14 days) } & LOU & $-0 \cdot 5 \pm 2 \cdot 1^{b}$ & $-2 \cdot 7 \pm 4 \cdot 4$ & $0 \cdot 4 \pm 1 \cdot 3$ & $-3 \cdot 0 \pm 3 \cdot 3^{a}$ & $-10 \cdot 8 \pm 2 \cdot 2^{b,+}$ & $-0 \cdot 8 \pm 1 \cdot 4$ \\
\hline & LEW & $-8 \cdot 0 \pm 3 \cdot 1^{a}$ & $1 \cdot 6 \pm 1 \cdot 8^{+}$ & $0 \cdot 1 \pm 1 \cdot 4^{*}$ & $4 \cdot 9 \pm 2 \cdot 1^{\mathrm{b}, \neq}$ & $0 \cdot 1 \pm 3 \cdot 1^{a, *}$ & $2 \cdot 9 \pm 2 \cdot 7^{+}$ \\
\hline
\end{tabular}

Sham-operated and ADX rats of each strain received paraffin pellets weighing about $100 \mathrm{mg}$ (Sham and ADX +0 groups respectively). The other ADX rats were given $100 \mathrm{mg}$ fused pellets composed of various percentages of corticosterone and cholesterol, and distributed among four experimental groups, $\mathrm{ADX}+12 \cdot 5$, $\mathrm{ADX}+25, \mathrm{ADX}+50$, and ADX +100 , treated with pellets containing $12 \cdot 5,25,50$, and $100 \%$ of corticosterone respectively for 2 weeks. For the same treatment, strains with different letters differ significantly $(P<0 \cdot 05)$. Differences from the ADX group: ${ }^{*} P<0 \cdot 05,{ }^{\dagger} P<0 \cdot 01,{ }^{\ddagger} P<0 \cdot 001$. 
only (strain $\times$ treatment interaction: $F_{10,134}=2 \cdot 56, P<0 \cdot 01$ ). Corticosterone treatment restored dose-dependently the weight gain to sham values in these strains. On the contrary, neither ADX nor low doses of corticosterone induced any effect on the weight gain of LOU rats. The highest corticosterone dose $(\mathrm{ADX}+100)$ induced weight loss in this strain (treatment effect in LOU rats: $F_{5,43}=12 \cdot 84$, $P<0 \cdot 01)$. Body weight curves showing the repeated data of each experimental group are presented in a supplementary figure available online at http://joe.endocrinology-journals. org/content/vol195/issue3/.

Body composition Body weight at killing. LEW sham rats showed a greater body weight than F344 (strain effect: $\left.F_{2,142}=215 \cdot 33, P<0 \cdot 001\right)$ or LOU rats $(P<0 \cdot 001$ versus F344 and LEW; Fig. 3a). ADX induced a strong weight loss in F344 and LEW rats only (strain $\times$ treatment interaction: $\left.F_{10,134}=1 \cdot 99, P<0 \cdot 05\right)$, whereas the substitution treatment by corticosterone restored the body weight of ADX groups to sham values. On the contrary, in post hoc analyses, the treatment effect did not reach significance in the LOU strain.

Thymus. ADX increased the thymus weight of the three strains (treatment effect: $F_{5,139}=20 \cdot 79, P<0 \cdot 001$; Fig. 3b), but to a greater extent in LOU (strain $\times$ treatment interaction: $F_{10,134}=2 \cdot 17, P<0 \cdot 05$; treatment effect in LOU: $F_{5,43}=$ $17 \cdot 02, P<0 \cdot 001)$ and LEW rats $\left(F_{5,43}=7 \cdot 73, P<0 \cdot 001\right)$ than in F344 rats $\left(F_{5,43}=4 \cdot 03, P<0 \cdot 05\right)$. Corticosterone treatment restored thymus weight to the sham value in LEW rats, whereas it induced a thymolysis beyond control values in LOU and F344 ADX + 100 groups (Fig. 3b).

Liver. Liver was heavier in F344 than LEW rats (strain effect: $F_{2,16}=5.51, P<0.01$; Fig. 3c). ADX decreased liver weights (treatment effect: $F_{5,139}=3.33, P<0 \cdot 01$ ), and the substitution corticosterone treatment dose dependently restored them to sham values, in F344 and LEW rats only (strain $\times$ treatment interaction: $\left.F_{10,134}=3.34, P<0 \cdot 001\right)$. The post hoc treatment effect did not reach significance in LOU rats.

Fat mass. Abdominal fat depots. Retroperitoneal, epididymal, and mesenteric fat depots were weighed and expressed in percentages of body weight, as shown in Fig. 4a-c. Irrespective of the experimental condition, LOU rats exhibited lower retroperitoneal fat mass than F344 and LEW rats (strain effect: $F_{2,142}=129 \cdot 17, \quad P<0 \cdot 001$ ). At moderate-to-high corticosterone concentrations, LOU rats also showed lower epididymal and mesenteric fat depots than F344 and LEW rats (strain effects: $F_{2,142}=239 \cdot 19$ and 114.97 respectively, $P<0.001)$. For all abdominal fat depots, the lipolytic effect of ADX and the adipogenic effect of corticosterone were measured in F344 and LEW rats only (strain $\times$ treatment interactions $F_{10,134}=4 \cdot 70,5 \cdot 10$, 4.64 in retroperitoneal, epididymal, and mesenteric fat respectively, $P<0 \cdot 001)$.
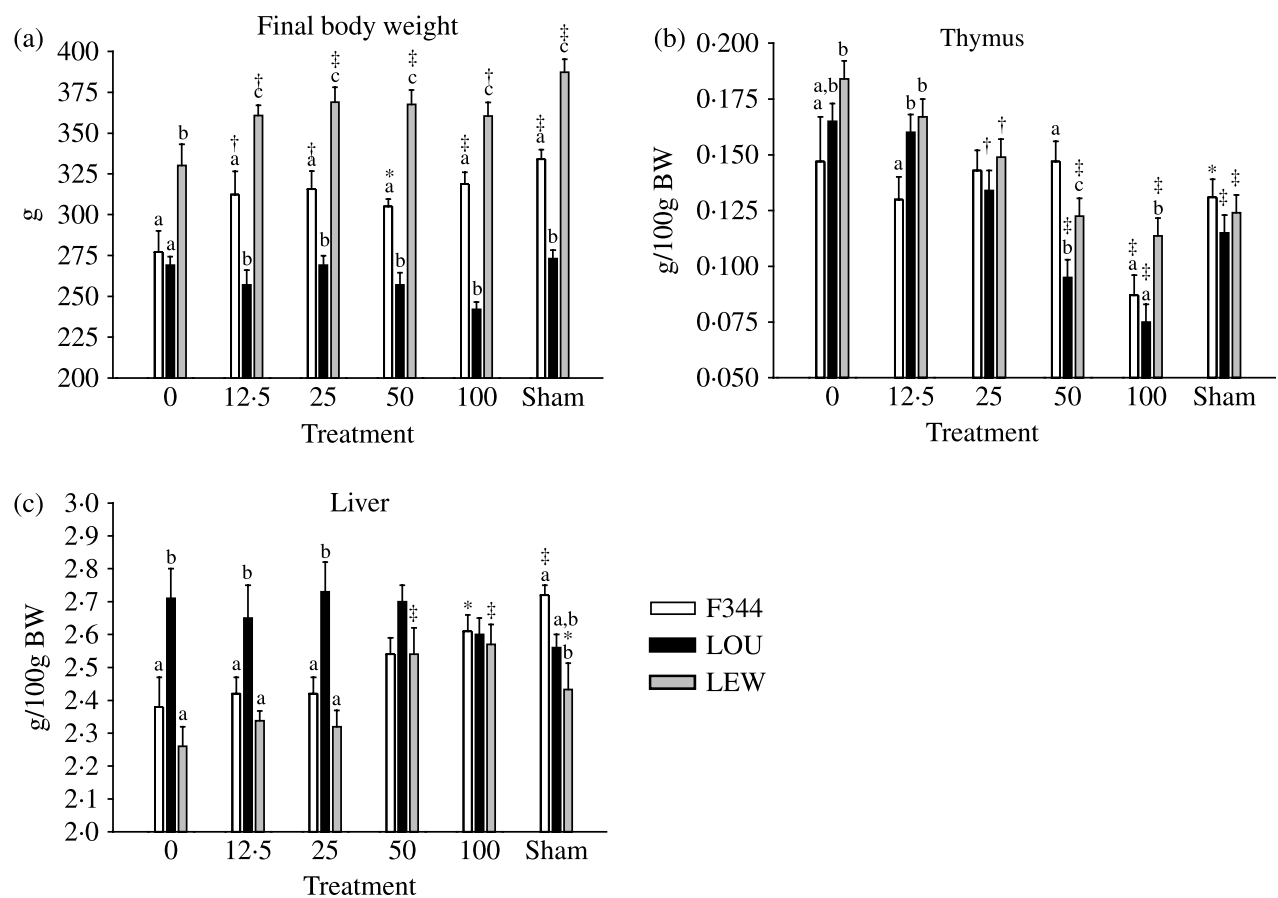

Figure 3 (a) Final body weight, (b) thymus, and (c) liver weights in F344, LOU, and LEW rats. ADX groups are represented on the abscissa by the percentage of corticosterone in their s.c. pellets $(0,12 \cdot 5,25,50$, and $100 \%$ respectively). Means were expressed according to the body weight (g/100 g BW). For the same treatment, strains with different letters differ significantly $(P<0 \cdot 05)$. Differences from the ADX group: $* P<0 \cdot 05$, ${ }^{+} P<0 \cdot 01,{ }^{\ddagger} P<0 \cdot 001$. 

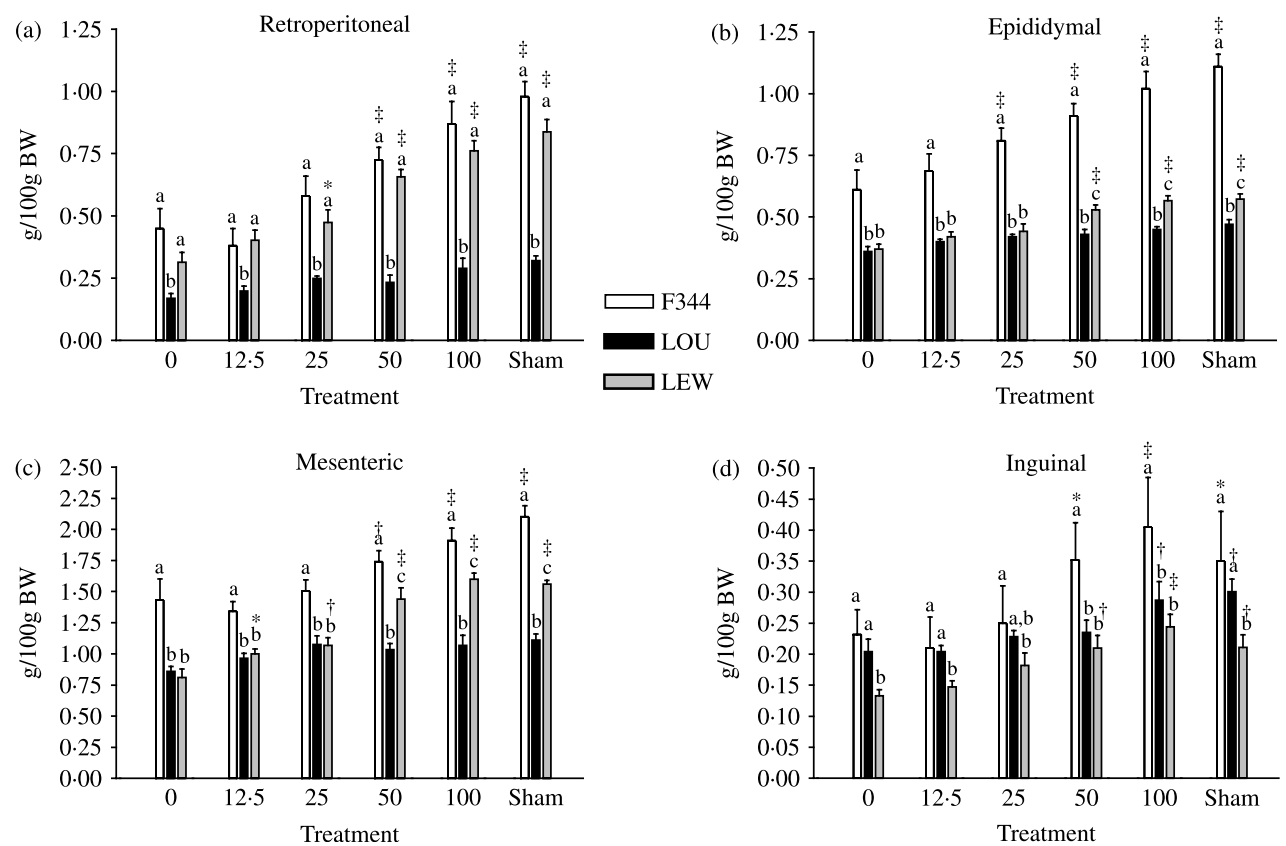

Figure 4 Percentages of abdominal fat depots $(a-c)$ and inguinal fat depot $(d$, representative of the s.c. fat) in F344, LOU, and LEW rats. ADX groups are represented on the abscissa by the percentage of corticosterone in their s.c. pellets $(0,12 \cdot 5,25,50$, and $100 \%$ respectively). Means were expressed according to the body weight (g/100 g BW). For the same treatment, strains with different letters differ significantly $(P<0 \cdot 05)$. Differences from the ADX group: ${ }^{*} P<0 \cdot 05,{ }^{+} P<0 \cdot 01,{ }^{\ddagger} P<0 \cdot 001$.

Inguinal fat depot (representative of the s.c. fat). LEW sham rats had lower inguinal fat depots than F344 or LOU rats (strain effect: $\left.F_{2,16}=6 \cdot 15, P<0 \cdot 01\right)$. The three strains presented the same regulation profile of their inguinal fat mass by corticosterone (Fig. 4d): a decrease induced by ADX and a dose-dependent restoration to control values by substitution treatment (treatment effect: $F_{5,139}=12 \cdot 16, P<0 \cdot 001$; no strain $\times$ treatment interaction).

\section{CRF expression in the paraventricular nucleus CRF} expression in the hypothalamic paraventricular nucleus was higher in LOU than that in F344 and LEW sham rats (strain effect: $\left.F_{2,16}=9 \cdot 14, P<0 \cdot 001\right)$. It was increased by ADX (treatment effect: $F_{5,120}=12.99, P<0.001 ; P<0.01$ versus sham value in F344, $P<0.001$ in LEW, NS in LOU; no strain $\times$ treatment interaction), and was inhibited by the 50 and $100 \mathrm{mg}$ corticosterone pellets in the same proportions in the three strains (Fig. 5a).

Hormonal and biochemical parameters $H P A$ axis. ACTH. ADX increased ACTH concentration (treatment effect: $\left.F_{5,139}=13 \cdot 47, P<0 \cdot 001\right)$, but to a greater extent in the F344 strain than in the others (strain $\times$ treatment interaction: $\left.F_{10,134}=2 \cdot 62, P<0 \cdot 01\right)$. The corticosterone replacement treatment decreased ACTH concentration when compared with ADX value from the lowest dose without any restoration to the sham value in F344 rats, with restoration to the sham level from the lowest dose in LOU rats, and from the $50 \mathrm{mg}$ dose in LEW rats (Fig. 5b).

CBG. F344 and LEW rats presented higher CBG concentrations than LOU rats (strain effect $F_{2,142}=21 \cdot 96, P<0 \cdot 001$ ). Plasma CBG concentrations were increased by ADX in the three strains (global treatment effect: $F_{5,139}=9 \cdot 86, P<0 \cdot 001$; ADX effect: $\left.F_{1,47}=29 \cdot 96, P<0 \cdot 001\right)$, but to a greater extent in F344 and LOU than in LEW rats (strain $\times$ treatment interaction in ADX effect: $F_{2,46}=3 \cdot 59, P<0 \cdot 05$; Fig. $5 c$ ).

Corticosterone. All ADX rats showed plasma corticosterone concentrations below assay detection limits (Fig. 5d). Substitution treatments induced the same dose-dependent increase profile of plasma corticosterone concentration in the three strains (from $34 \cdot 1 \pm 4 \cdot 5$ to $188 \cdot 3 \pm 17 \cdot 2 \mathrm{ng} / \mathrm{ml}$, treatment effect: $F_{5,139}=$ $48 \cdot 80, P<0 \cdot 001$; no strain $\times$ treatment interaction). In sham condition, LOU rats showed lower corticosterone concentrations than F344 and LEW rats (strain effect: $F_{2,16}=9 \cdot 15, P<0 \cdot 001$ ).

Metabolism. Glucose. Glucose levels were lower in LEW than those in F344 and LOU rats (strain effect: $F_{2,142}=15 \cdot 51$, $P<0 \cdot 001 ;$ Table 2). The global treatment effect was significant $\left(F_{5,139}=3 \cdot 03, P<0 \cdot 05\right)$, but post hoc analyses revealed a significant treatment effect in LOU only $\left(F_{5,43}=\right.$ $2 \cdot 50, P<0 \cdot 05)$. Glucose levels were reduced by ADX $\left(F_{5,43}=2 \cdot 98, P<0 \cdot 05\right)$ and restored to sham levels from the $50 \mathrm{mg}$ dose of corticosterone $(P<0 \cdot 05)$ in LOU.

Insulin. Neither treatment nor strain affected plasma insulin concentration. 
(a)

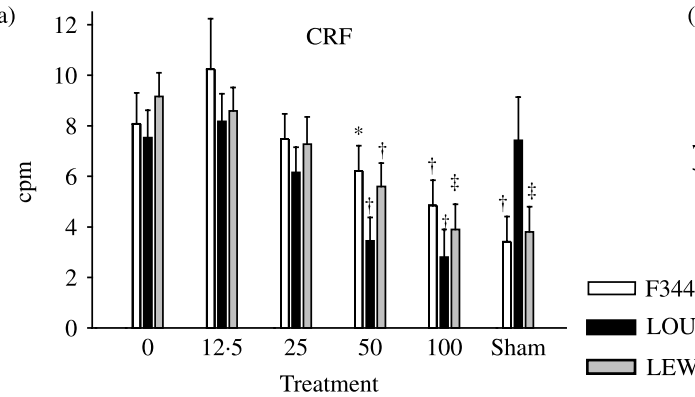

(b) 600$]$ a $\quad$ ACTH

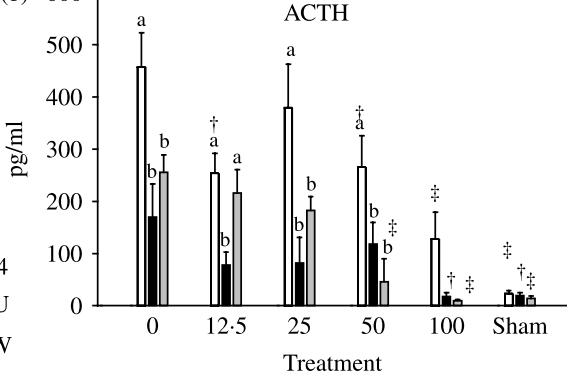

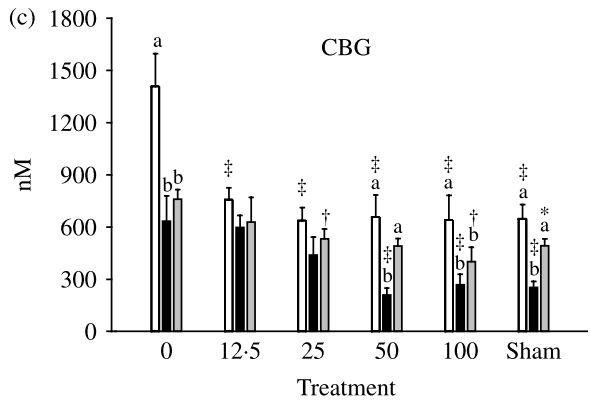

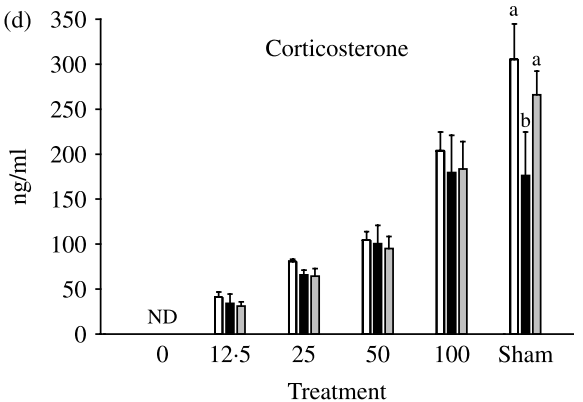

Figure 5 HPA axis parameters: CRF expression in the paraventricular nucleus (a) and plasma concentrations of ACTH (b), CBG (c) and corticosterone (d) in F344, LOU, and LEW rats. ADX groups are represented on the abscissa by the percentage of corticosterone in their s.c. pellets $(0,12 \cdot 5,25,50$, and $100 \%$ respectively). For the same treatment, strains with different letters differ significantly $(P<0 \cdot 05)$. Differences from the ADX group: ${ }^{*} P<0 \cdot 05,{ }^{\dagger} P<0 \cdot 01,{ }^{\ddagger} P<0 \cdot 001$. ND, not detectable.

Free fatty acids. Globally, the LOU strain presented lower plasma FFA concentration than the other strains (strain effect: $F_{2,138}=4 \cdot 70, P<0 \cdot 05$; Table 2).

Leptin. ADX decreased and high corticosterone increased plasma leptin concentrations in F344 and LEW rats only (strain $\times$ treatment interaction: $F_{10,131}=6 \cdot 67, \quad P<0 \cdot 001$; treatment effects: $F_{5,40}=17 \cdot 14, P<0 \cdot 001$ and $F_{5,43}=2 \cdot 97$, $P<0 \cdot 05$ respectively; Table 2 ).

Table 2 Plasma levels of metabolic parameters

\section{Discussion}

The first part of our study aimed to compare the HPA axis activity and reactivity to stress between F344 and LOU rats, previously shown to differ in food behavior and metabolism (Couturier et al. 2002, Helies et al. 2005). When compared with F344 rats, animals from the LOU strain showed lower corticosterone levels across the circadian cycle and during recovery following restraint

\begin{tabular}{|c|c|c|c|c|c|c|c|}
\hline & & Treatment & & & & & \\
\hline & Strain & $\overline{A D X}+0$ & $\mathrm{ADX}+12 \cdot 5$ & $\mathrm{ADX}+25$ & $\mathrm{ADX}+50$ & $\mathrm{ADX}+100$ & Sham \\
\hline Data & & & & & & & \\
\hline Glucose (g/l) & F344 & $1 \cdot 08 \pm 0 \cdot 17$ & $0 \cdot 92 \pm 0 \cdot 07^{\mathrm{a}}$ & $0 \cdot 89 \pm 0 \cdot 11^{\mathrm{a}}$ & $1 \cdot 11 \pm 0 \cdot 04^{\mathrm{a}}$ & $1 \cdot 07 \pm 0 \cdot 02^{a, b}$ & $1 \cdot 33 \pm 0 \cdot 05^{\mathrm{a}}$ \\
\hline & LOU & $0.87 \pm 0.07$ & $1 \cdot 04 \pm 0 \cdot 11^{\mathrm{a}}$ & $1 \cdot 06 \pm 0 \cdot 23^{a}$ & $1 \cdot 19 \pm 0 \cdot 14^{\mathrm{a}_{1} *}$ & $1 \cdot 31 \pm 0 \cdot 11^{\mathrm{a},+}$ & $1 \cdot 22 \pm 0 \cdot 16^{\mathrm{a}, *}$ \\
\hline & LEW & $0 \cdot 88 \pm 0 \cdot 16$ & $0 \cdot 70 \pm 0 \cdot 07^{\mathrm{b}}$ & $0 \cdot 61 \pm 0 \cdot 10^{b}$ & $0 \cdot 81 \pm 0 \cdot 09^{b}$ & $0 \cdot 84 \pm 0 \cdot 08^{\mathrm{b}}$ & $0 \cdot 89 \pm 0 \cdot 09^{b}$ \\
\hline Insulin (ng/ml) & F344 & $1.98 \pm 0.71$ & $2 \cdot 39 \pm 0 \cdot 61$ & $2 \cdot 74 \pm 0.64$ & $2 \cdot 05 \pm 0.52$ & $2 \cdot 93 \pm 0 \cdot 82$ & $4 \cdot 00 \pm 0 \cdot 89$ \\
\hline & LOU & $1.76 \pm 0.53$ & $2 \cdot 97 \pm 1 \cdot 22$ & $2 \cdot 32 \pm 1 \cdot 08$ & $2 \cdot 45 \pm 0 \cdot 73$ & $2 \cdot 25 \pm 0 \cdot 36$ & $3 \cdot 31 \pm 0 \cdot 79$ \\
\hline & LEW & $2 \cdot 52 \pm 0.70$ & $2.94 \pm 0.68$ & $3.71 \pm 0.97$ & $3 \cdot 02 \pm 0.79$ & $4 \cdot 25 \pm 0 \cdot 71$ & $4 \cdot 17 \pm 0.51$ \\
\hline FFA (mEq/l) & F344 & $0.59 \pm 0.04$ & $0.72 \pm 0.06$ & $0 \cdot 69 \pm 0 \cdot 02^{a, b}$ & $0.75 \pm 0 \cdot 04^{\mathrm{a}}$ & $0.72 \pm 0.08^{a}$ & $0.64 \pm 0.10$ \\
\hline & LOU & $0 \cdot 68 \pm 0 \cdot 15$ & $0 \cdot 78 \pm 0 \cdot 17$ & $0 \cdot 60 \pm 0 \cdot 15^{b}$ & $0 \cdot 58 \pm 0 \cdot 08^{\mathrm{b}}$ & $0 \cdot 50 \pm 0 \cdot 06^{\mathrm{b}}$ & $0 \cdot 55 \pm 0 \cdot 06$ \\
\hline & LEW & $0.78 \pm 0.05$ & $0.72 \pm 0.04$ & $0.83 \pm 0.08^{a}$ & $0.76 \pm 0.07^{a}$ & $0 \cdot 82 \pm 0 \cdot 10^{\mathrm{a}}$ & $0.67 \pm 0.07$ \\
\hline Leptin (ng/ml) & F344 & $0 \cdot 47 \pm 0 \cdot 25$ & $0 \cdot 24 \pm 0 \cdot 27$ & $0 \cdot 39 \pm 0 \cdot 23$ & $0 \cdot 76 \pm 0 \cdot 25$ & $1 \cdot 39 \pm 0 \cdot 23^{a_{1}+}$ & $3 \cdot 05 \pm 0 \cdot 21^{a, \neq}$ \\
\hline & LOU & $0 \cdot 23 \pm 0 \cdot 11$ & $0 \cdot 25 \pm 0 \cdot 13$ & $0 \cdot 56 \pm 0.15$ & $0 \cdot 72 \pm 0 \cdot 39$ & $0 \cdot 53 \pm 0 \cdot 12^{\mathrm{b}}$ & $0 \cdot 37 \pm 0 \cdot 13^{b}$ \\
\hline & LEW & $0 \cdot 53 \pm 0 \cdot 15$ & $0 \cdot 52 \pm 0 \cdot 06$ & $0 \cdot 28 \pm 0 \cdot 10$ & $0 \cdot 68 \pm 0 \cdot 28$ & $1 \cdot 14 \pm 0 \cdot 26^{\mathrm{a}, *}$ & $1 \cdot 15 \pm 0 \cdot 43^{\mathrm{c}, *}$ \\
\hline
\end{tabular}

Sham and ADX rats of each strain received paraffin pellets. ADX $+12 \cdot 5, A D X+25, A D X+50$, and $A D X+100$ groups were treated with pellets containing $12 \cdot 5$, 25,50 , and $100 \%$ of corticosterone respectively for 2 weeks. For the same treatment, strains with different letters differ significantly $(P<0 \cdot 05)$. Differences from the ADX group: ${ }^{*} P<0 \cdot 05,{ }^{\dagger} P<0 \cdot 01,{ }^{\ddagger} P<0 \cdot 001$. 
stress. In response to insulin treatment, glucose levels decreased in both sexes and strains, but to a greater extent in LOU than in F344 rats, in accordance with the insulin resistance described by Levy et al. (2002) in old F344 rats. Plasma corticosterone concentration was increased by insulin-induced hypoglycemia in both strains, but stayed higher in F344 than in LOU rats. Considering the disturbances in the HPA axis function playing a 'permissive' role in metabolic disturbances associated with obesity (Ljung et al. 2002), the nutritional differences observed between F344 and LOU rats could be associated with the functional differences in their HPA axis. To test this assumption, we compared the effects of ADX and corticosterone substitution after ADX on food intake, body weight gain, body composition, and biochemical parameters related to metabolism and HPA axis function between F344, LOU, and LEW males. LEW rats were added to the study of F344 and LOU rats in order to introduce a third condition of fat deposition related to HPA axis function. Indeed, the LEW strain has been described classically to exhibit a low HPA axis activity and reactivity to stress (similar to LOU; Dhabhar et al. 1995) and a high percentage of body fat mass (similar to F344; Nave et al. 2003).

According to Devenport et al. (1989), the effects of corticosterone on body weight follow a bell-shaped curve with increasing concentrations of the hormone as a result of different components of corticosterone actions on consummatory behaviors and metabolism (Tempel \& Leibowitz 1994, Santana et al. 1995). Optimal growth is reached at physiological levels. Body weight gain is reduced by ADX, restored to normal by low doses of corticosterone or MR agonists (Devenport et al. 1991), and decreased by high doses of corticosterone or GR agonists via catabolic effects on fat and protein stores (Santana et al. 1995). As we described previously (Helies et al. 2005), the body weight of F344 and LEW sham rats was markedly greater than that of LOU sham rats, in spite of an equal nose-tail length. F344 and LEW rats exhibited the classical weight loss after ADX, partly related to a decrease in their food intake. On the contrary, as described previously in Brown Norway rats (Marissal-Arvy et al. 2004), LOU rats showed an apparent insensitivity to ADX, suggesting the involvement of compensatory mechanisms for the lack of MR activation in these rats. The lowest doses of corticosterone (MR effect) restored the weight gain of F344 and LEW rats to sham values. A strong decrease in body weight gain was induced by the highest dose of corticosterone in LOU rats only, associated with a slight decrease in their food intake, suggesting that this strain is more sensitive to the catabolic effects exerted by corticosterone via GR. Thymus weight has been described classically as an index of GR activation in rodents (Levin et al. 1987, Cador et al. 1993, Young et al. 1995, Duclos et al. 2004). At equal corticosterone dose, thymolysis reflects GR sensitivity and/or efficiency. It reached significance from the $25 \mathrm{mg}$ corticosterone treatment in LOU and LEW rats, whereas it was significant in F344 rats with the $100 \mathrm{mg}$ dose only. This marked GR effect of corticosterone in the LOU and LEW strains could involve a higher bioavailability of corticosterone (rise in the free active fraction of the steroid) and/or a greater efficiency of GR transduction processes (Miller et al. 1997).

The body fat content and distribution are mainly controlled by the sympathetic nervous system (SNS, lipolytic; Bartness \& Bamshad 1998, Fliers et al. 2003) and the HPA axis (Bjorntorp 1991). Low doses of corticosterone or aldosterone via $M R$ have been described to exert lipogenic effects in rats (Devenport et al. 1991). Glucocorticoids are described classically to induce lipolysis and proteolysis to provide energetic fuels for the stress response (Smith \& Vale 2006). They are also known to increase preadipocyte differentiation (Joyner et al. 2000) and adipogenesis via GR synergistically with insulin in the abdominal area (Fried et al. 1993, Ramsay 1996). The proteolysis induced by GR activation is more marked than the lipolysis, altering the body distribution of lipid stores to increase abdominal fat mass at the expense of muscular mass (Sjögren et al. 1994, Abate \& Garg 1995, Wajchenberg 2000). A recent study conducted by Zhang et al. (2006) showed that specific activation of the hypothalamic MR stimulates the SNS. On the contrary, glucocorticoids are described classically to decrease norepinephrine synthesis, release, and reuptake via GR in the central nervous system (Kvetnansky et al. 1995). The HPA axis and SNS also interact continuously in periphery as, according to biological conditions, i.e. the presence of insulin or not, glucocorticoids can inhibit or potentiate catecholamine lipolytic action respectively (Ottosson et al. 2000, Girod \& Brotman 2003). In sham condition, LOU rats showed a lower abdominal fat mass than F344 and LEW rats. The resistance to diet-induced obesity and the leanness of LOU rats could originate in the HPA axis hypoactivity observed in this study, and/or sympathetic hyperactivity (as suggested recently by Perrin et al. 2003). ADX decreased the percentage of body fat mass of F344 and LEW rats. On the contrary, in LOU rats, we did not measure any effect of ADX on abdominal fat depot. This characteristic might partly contribute to the lack of weight loss after ADX in this strain. As expected according to the involvement of glucocorticoids in the regulation of fat depots summed up as above, and as described classically in other rat strains (Devenport et al. 1991, Tempel \& Leibowitz 1994), the body fat proportion was dose dependently increased by the substitution corticosterone treatment in the F344 and LEW strains. This effect was induced by different corticosterone doses according to the strain and the fat pad considered: $12.5 \mathrm{mg}$ pellet in LEW versus $50 \mathrm{mg}$ in F344 rats for the mesenteric fat depot, $25 \mathrm{mg}$ versus $50 \mathrm{mg}$ respectively for the retroperitoneal fat, $50 \mathrm{mg}$ versus $25 \mathrm{mg}$ for the epididymal fat, and $50 \mathrm{mg}$ in both strains for the inguinal (s.c.) fat. Therefore, F344/LEW and fat mass differences could involve various $\mathrm{MR} / \mathrm{GR}$ actions on a background of different nervous (SNS) and/or hormonal (sexual steroids, insulin) regulations (McCarty 2001). On the contrary, LOU rats were insensitive to the adipogenic effect exerted by corticosterone on abdominal fat. This model is all the more interesting since the visceral fat mass is involved in the metabolic disturbances linked to obesity (McCarty 2001, Pitombo et al. 2006), which 
are moreover aggravated by glucocorticoids. At last, this process might contribute to the greater weight loss induced by the highest dose of corticosterone in LOU, by a loss of muscular mass not compensated by an increasing abdominal fat depot. On the contrary, corticosterone induced the expected increase of s.c. fat in LOU. These differential effects of corticosterone on fats illustrate regional specificity (visceral versus s.c.) of the regulations exerted by the HPA axis and SNS. For instance, they could involve the greater norepinephrinergic tone (i.e., lipolysis) suggested in abdominal versus peripheral fat by Bartness \& Bamshad (1998), associated or not with a high central MR activation stimulating SNS tone in LOU rats (Zhang et al. 2006). Previously, we performed a genetic study on a Brown Norway $\times$ F344 F2 population that revealed a gain of function mutation in the Brown Norway MR, which was involved in the insensitivity of Brown Norway rats to ADX (Marissal-Arvy et al. 2004). An MR harboring a gain of function could potentiate GR-related catabolic and feedback effects, notably by heterodimerization (Derfoul et al. 2000). It could also induce a high central stimulation of the SNS (Zhang et al. 2006) in lean rat strains such as the Brown Norway and LOU strains. Further investigations will be conducted to find the possible common denominator between functional differences in corticosteroid receptors, specific involvement of $M R$ versus $G R$ in the central regulation of SNS by corticosterone, and the nutritional characteristics of our rat models.

As described classically in the literature (Kumar \& Leibowitz 1988), the liver weight was decreased by ADX and returned to control by high doses of corticosterone via GR in F344 and LEW rats. On the contrary in LOU, as for body weight and fat, the liver weight was modified neither by ADX nor by corticosterone substitution treatment.

To complete the comparison of the regulation exerted by corticosterone on body composition between F344, LOU, and LEW rats, we investigated corticosterone action on parameters related to the HPA axis (hypothalamic CRF expression, plasma ACTH, and CBG) and metabolism (plasma glucose, insulin, FFA, and leptin). The corticosterone effect on HPA axis is the reflection of $M R / G R$ activation and the negative feedback exerted by this steroid on its own secretion. In sham condition, CRF expression in the hypothalamic paraventricular nucleus did not differ across the three strains, confirming the previous results obtained by Rivest and Rivier in F344 and LEW males (Rivest \& Rivier 1994). ADX increased CRF expression in F344 and LEW rats only. CRF hypothalamic expression was decreased from the $50 \mathrm{mg}$ corticosterone treatment in the three strains probably via classical GR activation (Tanimura \& Watts 1998). Control ACTH concentrations did not differ across strains. ADX increased ACTH to a greater extent in F344 than in LOU and LEW rats. ACTH was brought back to sham values by corticosterone in a dose-dependent manner and in the same proportion in the three strains. This effect reached significance from the lowest corticosterone dose in F344 rats, implicating MR-related regulation of plasma ACTH in this strain, as already described in Sprague-Dawley rats by Levin et al. (1987). In sham groups and at the 50 and $100 \mathrm{mg}$ corticosterone doses, LOU rats showed lower plasma CBG concentrations than F344 and LEW rats. Therefore, in LOU rats, the greater free fraction of corticosterone might contribute to the higher effects induced by corticosterone on their carcass, thymus weight, or CRF.

Corticosterone exerts classically a GR-related hyperglycemic effect via the mobilization of carbohydrate body stores (in liver and muscles), gluconeogenesis (Goldstein et al. 1993, Opherk et al. 2004), and anti-insulin effects on glucose uptake and utilization by tissues (Andrews \& Walker 1999). Whenever corticosterone was present in plasma (control or pellet treatment), glucose levels of LEW rats were lower than those of LOU or F344 rats and than those already published (Levy et al. 2002). To our knowledge, this peculiarity of LEW rats has not been explored yet. Glucose levels were decreased by ADX in LOU rats only, and then restored classically to sham levels by the highest corticosterone doses. Insulin concentrations were the same in the three rat strains in control and were not altered by ADX. Plasma insulin tended to be increased by the highest doses of corticosterone, but this effect did not reach significance in our study. ADX and corticosterone effects on insulin have been described more clearly by other authors, but in other rat strains and after different duration of ADX (Dallman et al. 1993, La Fleur et al. 2004). In sham condition, plasma FFA concentrations did not differ across strains. We observed much lower FFA concentration in LOU than that in F344 and LEW rats at moderate-to-high doses of corticosterone. Nevertheless, the high SNS tone (Perrin et al. 2003) associated with the greater corticosterone effects in LOU would be expected to induce a high basal lipolysis. In this case, FFA would be instantly used for gluconeogenesis or oxidized in this strain. This assumption will be explored by measurements with indirect colorimetry. In sham condition, the strain differences in plasma leptin levels reflected exactly the differences observed in fat mass depot, i.e., F344 $>$ LEW $>$ LOU rats. As described classically in the literature (Mora \& Pessin 2002, Zhang et al. 2005), plasma leptin was decreased by ADX in F344 and LEW rats. Leptin secretion followed the fat mass increase but was not restored to the sham level by corticosterone supplementation in these rats, suggesting the involvement of other adrenal factor(s) in the regulation of leptin production. As for abdominal fat mass, we observed neither ADX nor corticosterone effect on leptin concentration in LOU rats.

In conclusion, we showed here that despite the greatest effects of high doses of corticosterone on thymus, carcass weight, hypothalamic CRF, or plasma CBG in the LOU strain when compared with the F344 and LEW strains, this strain was completely insensitive to the anabolic effects of corticosterone, i.e., on body weight, liver, and abdominal fat depots. The knowledge of the mechanisms involved could bring critical information on important features of this strain, its leanness and insensitivity to diet-induced obesity, as well as its longevity with healthy aging (Veyrat-Durebex et al. 2005). The LOU rat strain should be useful as a model for the resistance to the central adipogenic effects exerted by glucocorticoids. Molecular mechanisms implicated in such a resistance in abdominal adipose 
tissues should be compared with other models of glucocorticoid resistance (Schaaf \& Cidlowski 2002) to identify fat specificity and potential therapeutic targets to prevent the metabolic syndrome.

\section{Acknowledgements}

This work was partly supported by the Institut de Recherche en Nutrition Humaine d'Aquitaine and the INSERM ATC Nutrition. The authors declare that there is no conflict of interest that would prejudice the impartiality of this scientific work.

\section{References}

Abate N \& Garg A 1995 Heterogeneity in adipose tissue metabolism: causes, implications and management of regional adiposity. Progress in Lipid Research $3453-70$.

Alliot J, Boghossian S, Jourdan D, Veyrat-Durebex C, Pickering G, MeynialDenis D \& Gaumet N 2002 The LOU/c/jall rat as an animal model of healthy aging? Journals of Gerontology. Series A, Biological Sciences and Medical Sciences 57 B312-B320.

Andrews RC \& Walker BR 1999 Glucocorticoids and insulin resistance: old hormones, new targets. Clinical Science 96 513-523.

Bartness TJ \& Bamshad M 1998 Innervation of mammalian white adipose tissue: implications for the regulation of total body fat. American Journal of Physiology. Regulatory, Integrative and Comparative Physiology 275 R1399-R1411.

Bjorntorp P 1991 Adipose tissue distribution and function. International Journal of Obesity 2 67-81.

Cador M, Dulluc J \& Mormede P 1993 Modulation of the locomotor response to amphetamine by corticosterone. Neuroscience 56 981-988.

Chaouloff F 1994 Effects of repeated 2-deoxy-D-glucose administration on ingestive, psychological, and 5-HT-related behaviours in the rat. Neuropharmacology 33 693-703.

Couturier K, Servais S, Koubi H, Sempore B, Sornay-Mayet MH, CottetEmard JM, Lavoie JM \& Favier R 2002 Metabolic characteristics and body composition in a model of anti-obese rats (Lou/C). Obesity Research 10 188-195.

Dallman MF, Strack AM, Akana SF, Bradbury MJ, Hanson ES, Scribner KA \& Smith M 1993 Feast and famine: critical role of glucocorticoids with insulin in daily energy flow. Frontiers in Neuroendocrinology 14 303-347.

Derfoul A, Robertson NM, Hall DJ \& Litwack G 2000 The N-terminal domain of the mineralocorticoid receptor modulates both mineralocorticoid receptor- and glucocorticoid receptor-mediated transactivation from $\mathrm{Na}$ /K ATPase beta1 target gene promoter. Endocrine 13 287-295.

Devenport L, Knehans A, Sundstrom A \& Thomas T 1989 Corticosterone's dual metabolic actions. Life Sciences 45 1389-1396.

Devenport L, Knehans A, Thomas T \& Sundstrom A 1991 Macronutrient intake and utilization by rats: interactions with type I adrenocorticoid receptor stimulation. American Journal of Physiology. Regulatory, Integrative and Comparative Physiology 260 R73-R81.

Dhabhar FS, Miller AH, McEwen BS \& Spencer RL 1995 Differential activation of adrenal steroid receptors in neural and immune tissues of Sprague Dawley, Fischer 344, and Lewis rats. Journal of Neuroimmunology 56 77-90.

Duclos M, Gouarne C, Martin C, Rocher C, Mormede P \& Letellier T 2004 Effects of corticosterone on muscle mitochondria identifying different sensitivity to glucocorticoids in Lewis and Fischer rats. American Journal of Physiology. Endocrinology and Metabolism 286 E159-E167.

La Fleur SE, Akana SF, Manalo SL \& Dallman MF 2004 Interaction between corticosterone and insulin in obesity: regulation of lard intake and fat stores. Endocrinology 145 2174-2185.

Fliers E, Kreier F, Voshol PJ, Havekes LM, Sauerwein HP, Kalsbeek A, Buijs RM \& Romijn JA 2003 White adipose tissue: getting nervous. Journal of Neuroendocrinology 15 1005-1010.
Fried SK, Russell CD, Grauso NL \& Brolin RE 1993 Lipoprotein lipase regulation by insulin and glucocorticoid in subcutaneous and omental adipose tissues of obese women and men. Journal of Clinical Investigation 92 2191-2198.

Gibson EL 2006 Emotional influences on food choice: sensory, physiological and psychological pathways. Physiology and Behavior 89 53-61.

Girod JP \& Brotman DJ 2003 The metabolic syndrome as a vicious cycle: does obesity beget obesity? Medical Hypotheses $60584-589$.

Goldstein RE, Wasserman DH, McGuinness OP, Lacy DB, Cherrington AD \& Abumrad NN 1993 Effects of chronic elevation in plasma cortisol on hepatic carbohydrate metabolism. American Journal of Physiology. Endocrinology and Metabolism 264 E119-E127.

Helies JM, Diane A, Langlois A, Larue-Achagiotis C, Fromentin G, Tome D, Mormede P \& Marissal-Arvy N 2005 Comparison of fat storage between Fischer 344 and obesity-resistant Lou/C rats fed different diets. Obesity Research 13 3-10.

Johnson EO, Kamilaris TC, Calogero AE, Glod PW \& Chrousos GP 2005 Experimentally-induced hyperthyroidism is associated with activation of the rat hypothalamic-pituitary-adrenal axis. European Journal of Endocrinology 153 177-185.

Joyner JM, Hutley LJ \& Cameron DP 2000 Glucocorticoid receptors in human preadipocytes: regional and gender differences. Journal of Endocrinology 166 145-152.

Karteszi M, Dallman MF, Makara GB \& Stark E 1982 Regulation of the adrenocortical response to insulin-induced hypoglycemia. Endocrinology $111535-541$.

Kumar BA \& Leibowitz SF 1988 Impact of acute corticosterone administration on feeding and macronutrient self-selection patterns. American Journal of Physiology 254 R222-R228.

Kvetnansky R, Pacak K, Fukuhara K, Viskupic E, Hiremagalur B, Nankova B, Goldstein DS, Sabban EL \& Kopin IJ 1995 Sympathoadrenal system in stress. Interaction with the hypothalamic-pituitary-adrenocortical system. Annals of the New York Academy of Sciences 771 131-158.

Levin N, Akana SF, Jacobson L, Kuhn RW, Siiteri PK \& Dallman MF 1987 Plasma adrenocorticotropin is more sensitive than CBG production or thymus weight to inhibition by corticosterone in rats. Endocrinology 121 1104-1110.

Levin BE, Dunn-Meynell AA, Balkan B \& Keesey RE 1997 Selective breeding for diet-induced obesity and resistance in Sprague-Dawley rats. American Journal of Physiology. Regulatory, Integrative and Comparative Physiology 273 R725-R730.

Levy JR, Davenport B, Clore JN \& Stevens W 2002 Lipid metabolism and resistin gene expression in insulin-resistant Fischer 344 rats. American Journal of Physiology. Endocrinology and Metabolism 282 E626-E633.

Li HJ, Ji CY, Wang W \& Hu YH 2005 A twin study for serum leptin, soluble leptin receptor, and free insulin-like growth factor-I in pubertal females. Journal of Clinical Endocrinology and Metabolism 90 3659-3664.

Ljung T, Ottosson M, Ahlberg AC, Eden S, Oden B, Okret S, Bronnegard M, Stierna P \& Bjorntorp P 2002 Central and peripheral glucocorticoid receptor function in abdominal obesity. Journal of Endocrinological Investigation 25 229-235.

Loos RJ \& Rankinen T 2005 Gene-diet interactions on body weight changes. Journal of the American Dietetic Association 105 S29-S34.

Marissal-Arvy N, Lombès M, Petterson J, Moisan M-P \& Mormede P 2004 Gain of function mutation in the mineralocorticoid receptor of the Brown Norway rat. Journal of Biological Chemistry 279 39232-39239.

McCarty MF 2001 Modulation of adipocyte lipoprotein lipase expression as a strategy for preventing or treating visceral obesity. Medical Hypotheses 57 192-200.

Miller AH, Spencer RL, Pearce BD, Pisell TL, Tanapat P, Leung JJ, Dhabhar FS, McEwen BS \& Biron CA 1997 Effects of viral infection on corticosterone secretion and glucocorticoid receptor binding in immune tissues. Psychoneuroendocrinology 22 455-474.

Mora S \& Pessin JE 2002 An adipocentric view of signaling and intracellular trafficking. Diabetes/Metabolism Research and Reviews 18 345-356.

Nave H, Kuhlmann S, Brabant G \& Pabst R 2003 Changes in cerebral endothelial barrier antigen, without alteration of permeability for intravenously injected leptin in diet-induced obesity in rats. Experimental and Toxicologic Pathology 55 45-49. 
Opherk C, Tronche F, Kellendonk C, Kohlmuller D, Schulze A, Schmid W \& Schutz G 2004 Inactivation of the glucocorticoid receptor in hepatocytes leads to fasting hypoglycemia and ameliorates hyperglycemia in streptozotocin-induced diabetes mellitus. Molecular Endocrinology 18 1346-1353.

Osako Y, Koike K, Kiyama H, Sakamoto Y, Masuhara K, Segawa T, Inoue M \& Murata Y 1999 Insulin-induced hypoglycemia activates a chemokinergic neuronal pathway in the hypothalamo-pituitary system. Neuropeptides 33 271-275.

Ottosson M, Lonnroth P, Bjorntorp P \& Eden S 2000 Effects of cortisol and growth hormone on lipolysis in human adipose tissue. Journal of Clinical Endocrinology and Metabolism 85 799-803.

Perrin D, Mamet J, Geloen A, Morel G, Dalmaz Y \& Pequignot JM 2003 Sympathetic and brain monoaminergic regulation of energy balance in obesity-resistant rats (Lou/C). Autonomic Neuroscience 109 1-9.

Pitombo C, Araujo EP, De Souza CT, Pareja JC, Geloneze B \& Velloso LA 2006 Amelioration of diet-induced diabetes mellitus by removal of visceral fat. Journal of Endocrinology 191 699-706.

Ramsay TG 1996 Fat cells. Endocrinology and Metabolism Clinics of North America 25 847-887.

Ribot E, Lafon P, Ciofi P, Sarrieau A, Tramu G \& Corio M 2003 Prostaglandins mediate lipopolysaccharide effects upon cholecystokinin and neurotensin phenotypes in neuroendocrine corticotropin-releasing hormone neurons: in situ hybridization evidence in the rat. Neuroscience 120 643-648.

Rivest S \& Rivier C 1994 Stress and interleukin-1 beta-induced activation of c-fos, NGFI-B and CRF gene expression in the hypothalamic PVN: comparison between Sprague-Dawley, Fischer-344 and Lewis rats. Journal of Neuroendocrinology 6 101-117.

Santana P, Akana SF, Hanson ES, Strack AM, Sebastian RJ \& Dallman MF 1995 Aldosterone and dexamethasone both stimulate energy acquisition whereas only the glucocorticoid alters energy storage. Endocrinology 136 2214-2222.

Sarrieau A \& Mormede P 1998 Hypothalamic-pituitary-adrenal axis activity in the inbred Brown Norway and Fischer 344 rat strains. Life Sciences 62 1417-1425.

Sarrieau A, Chaouloff F, Lemaire V \& Mormede P 1998 Comparison of the neuroendocrine responses to stress in outbred, inbred and F1 hybrid rats. Life Sciences 63 87-96.

Schaaf MJ \& Cidlowski JA 2002 Molecular mechanisms of glucocorticoid action and resistance. Journal of Steroid Biochemistry and Molecular Biology 83 $37-48$.
Schalling M, Johansen J, Nordfors L \& Lonnqvist F 1999 Genes involved in animal models of obesity and anorexia. Journal of Internal Medicine 245 613-619.

Seematter G, Binnert C, Martin J-L \& Tappy L 2004 Relationship between stress, inflammation and metabolism. Current Opinion in Clinical Nutrition and Metabolic Care 7 169-173.

Sjögren J, Weck M, Nilsson A, Ottosson M \& Bjorntorp P 1994

Glucocorticoid hormone binding to rat adipocytes. Biochimica et Biophysica Acta 1224 17-21.

Smith SM \& Vale WW 2006 The role of the hypothalamic-pituitary-adrenal axis in neuroendocrine responses to stress. Dialogues in Clinical Neuroscience $\mathbf{8}$ 383-395.

Tanimura SM \& Watts AG 1998 Corticosterone can facilitate as well as inhibit corticotropin-releasing hormone gene expression in the rat hypothalamic paraventricular nucleus. Endocrinology 139 3830-3836.

Tempel DL \& Leibowitz SF 1994 Adrenal steroid receptors: interactions with brain neuropeptide systems in relation to nutrient intake and metabolism. Journal of Neuroendocrinology 6 479-501.

Veyrat-Durebex C, Alliot J \& Gaudreau P 2005 Regulation of the pituitary growth hormone-releasing hormone receptor in ageing male and female LOU rats: new insights into healthy ageing. Journal of Neuroendocrinology 17 691-700.

Wajchenberg BL 2000 Subcutaneous and visceral adipose tissue: their relation to the metabolic syndrome. Endocrine Reviews 21 697-738.

Young EA, Kwak SP \& Kottak J 1995 Negative feedback regulation following administration of chronic exogenous corticosterone. Journal of Neuroendocrinology 7 37-45.

Zhang F, Chen Y, Heiman M \& Dimarchi R 2005 Leptin: structure, function and biology. Vitamins and Hormones 71 345-347.

Zhang Z-H, Kang Y-M, Yu Y, Wei S-G, Schmidt TJ, Johnson AK \& Felder RB 2006 Eleven beta-hydroxysteroid dehydrogenase type 2 activity in hypothalamic paraventricular nucleus modulates sympathetic excitation. Hypertension 48 127-133.

\section{Received in final form 3 September 2007 \\ Accepted 2 October 2007 \\ Made available online as an Accepted Preprint 2 October 2007}

